(2) Open Access Full Text Article

REVIEW

\title{
Assessing the role of cognitive behavioral therapy in the management of chronic nonspecific back pain
}

This article was published in the following Dove Press journal: Journal of Pain Research

10 October 2012

Number of times this article has been viewed

\author{
Vigdis Sveinsdottir' \\ Hege R Eriksen ${ }^{1,2}$ \\ Silje Endresen Reme ${ }^{1,3}$ \\ 'Uni Health, Uni Research, Bergen, \\ Norway; ${ }^{2}$ Department of Health \\ Promotion and Development, \\ University of Bergen, Bergen, Norway; \\ ${ }^{3}$ Department of Environmental Health, \\ Harvard School of Public Health, \\ Boston, MA, USA
}

Purpose: The aim of this study is to provide a narrative review of the current state of knowledge of the role of cognitive behavioral therapy (CBT) in the management of chronic nonspecific back pain.

Methods: A literature search on all studies published up until July 2012 (PubMed and PsycINFO) was performed. The search string consisted of 4 steps: cognitive behavioral therapy/ treatment/management/modification/intervention, chronic, back pain (MeSH term) or low back pain (MeSH term), and randomized controlled trial (MeSH term). The conclusions are based on the results from randomized controlled trials (RCTs) and reviews of RCTs. Interventions were not required to be pure CBT interventions, but were required to include both cognitive and behavioral components.

Results: The search yielded 108 studies, with 46 included in the analysis. Eligible intervention studies were categorized as CBT compared to wait-list controls/treatment as usual, physical treatments/exercise, information/education, biofeedback, operant behavioral treatment, lumbar spinal fusion surgery, and relaxation training. The results showed that CBT is a beneficial treatment for chronic back pain on a wide range of relevant variables, especially when compared to wait-list controls/treatment as usual. With regards to the other comparison treatments, results were mixed and inconclusive.

Conclusion: The results of this review suggest that CBT is a beneficial treatment for chronic nonspecific back pain, leading to improvements in a wide range of relevant cognitive, behavioral and physical variables. This is especially evident when CBT is compared to treatment as usual or wait-list controls, but mixed and inconclusive when compared with various other treatments. Multidisciplinary and transdisciplinary interventions that integrate CBT with other approaches may represent the future direction of management of chronic back pain, with treatments modified for specific circumstances and stakeholders. There is a need for future intervention studies to be specific in their use of cognitive behavioral elements, in order for results to be comparable.

Keywords: low back pain, pain management, problem-solving therapy, randomized controlled trials, review

\section{Background}

This is a review of the role of cognitive behavioral therapy (CBT) in the management of chronic and nonspecific back pain, with a main focus on low back pain (LBP). CBT involves a combination of cognitive and behavioral techniques and is based on the assumption that the individual's way of thinking motivates and affects behavior and emotions. In CBT, the idea is to target maladaptive thoughts and behaviors using
Correspondence: Vigdis Sveinsdottir Uni Health, POB 7810, NO-5020

Bergen, Norway

Tel +4755 589959

Fax +4755 589878

Email vigdis.sveinsdottir@uni.no 
structured techniques that aim to identify, challenge, and subsequently change patterns of unhelpful thoughts and behaviors. ${ }^{1,2}$ Common techniques used are behavioral experiments (eg, through gradual exposure to feared situations and/or activities) and cognitive restructuring (eg, through replacing unhelpful beliefs with alternative, more helpful beliefs). The therapeutic alliance between the patient and the therapist is an important aspect of the CBT and involves a collaborative approach from the therapist and active participation from the patient. The therapy is usually structured and short-term and involves explicit goals broken down into manageable subgoals with regular homework assignments. ${ }^{1}$ The therapy exists in many shapes and forms, and elements of CBT are frequently used alone or in combination with other approaches. It can be provided by psychologists or other health care professionals, and may be organized as individual therapy, in group sessions, or even as an internetbased intervention.

CBT is widely applicable across situations and beyond the initial problem for which the patient may seek treatment, though it has been specialized and adapted for use within a number of specific disorders ranging from depression, anxiety, and insomnia, to substance abuse and psychosis. CBT has also become increasingly popular for a wide variety of chronic pain conditions, particularly for chronic LBP. LBP involves pain and discomfort localized below the costal margin and above the inferior gluteal folds, with or without referred leg pain, ${ }^{3}$ and chronic LBP is commonly referred to as persistent pain that has lasted for more than 12 weeks. ${ }^{4}$ The suffering in the chronic stage of LBP goes beyond the experience of bodily pain and often affects every aspect of the individual's life, including family and work. ${ }^{4,5}$

Most LBP is nonspecific and without any objective findings or specific pathology. Objective findings of nerve root or spinal pathology constitute less than $15 \%$ of all back pain episodes. ${ }^{4}$ Although there is little scientific evidence of the prevalence of chronic LBP, estimates suggest a lifetime prevalence of about $23 \% .{ }^{4}$ Chronic LBP thus constitutes a pronounced societal burden, across both different countries ${ }^{6-8}$ and diverse populations. ${ }^{9-12}$

Chronic nonspecific LBP is an example of the low correlations that can occur between pathology and pain behavior. ${ }^{13}$ It appears to be more destructive and disruptive than acute pain, which may act as a useful short-term warning signal. Many patients with chronic nonspecific LBP develop negative expectations about the consequences of their pain and about their personal abilities to cope with it and are reluctant to resume normal activity and work out of fear of further injury. ${ }^{14,15}$ The prolonged recovery from chronic LBP may be linked to such unhelpful coping strategies and various other individual and psychosocial factors that can be targeted through CBT. ${ }^{16-19}$

A large number of studies evaluating the effects of CBT for chronic LBP have been conducted. However, the examined studies vary greatly in their study design and treatment characteristics, and many studies merely use elements of cognitive and/or behavioral techniques. Emphasis on different therapeutic techniques and decisions about which studies should be categorized as true CBT interventions are important issues to consider when reviewing the literature on CBT. Despite several previous reviews of the various interventions for chronic $\mathrm{LBP},{ }^{20-25}$ there are, to our knowledge, no reviews so far providing a broad synthesis in which the role of CBT in the management of chronic nonspecific back pain is assessed and considered.

The aim of this paper is to provide a narrative review of the current state of knowledge of the role of CBT in the management of chronic nonspecific back pain, with a main focus on LBP. When evaluating the effects of CBT, the conclusions are based on results from randomized controlled trials (RCTs) and reviews of RCTs. Furthermore, to give a broader perspective of the role of CBT in the management of chronic back pain, some data and conclusions from additional studies are also taken into consideration when discussing the results.

\section{Methods \\ Search strategy}

The literature search was conducted on all studies published up until July 2012 through the search engine PubMed and the PsycINFO database. Additional articles were also identified through other sources such as reference lists and personal communication. See Figure 1 for the flow chart of the article selection process.

The search string consisted of 4 steps: Cognitive behavioral therapy/treatment/management/modification/ intervention and chronic and back pain (MeSH term) or low back pain (MeSH term) and randomized controlled trial (MeSH term). The search included only papers written in English, and included both British and American spellings of all relevant words.

\section{Inclusion and exclusion of studies}

The main reasons for exclusion of studies were study design (only RCTs were included in the results), lack of relevance, noncognitive or nonbehavioral interventions, and irrelevant patient groups. See Figure 1 for details. 


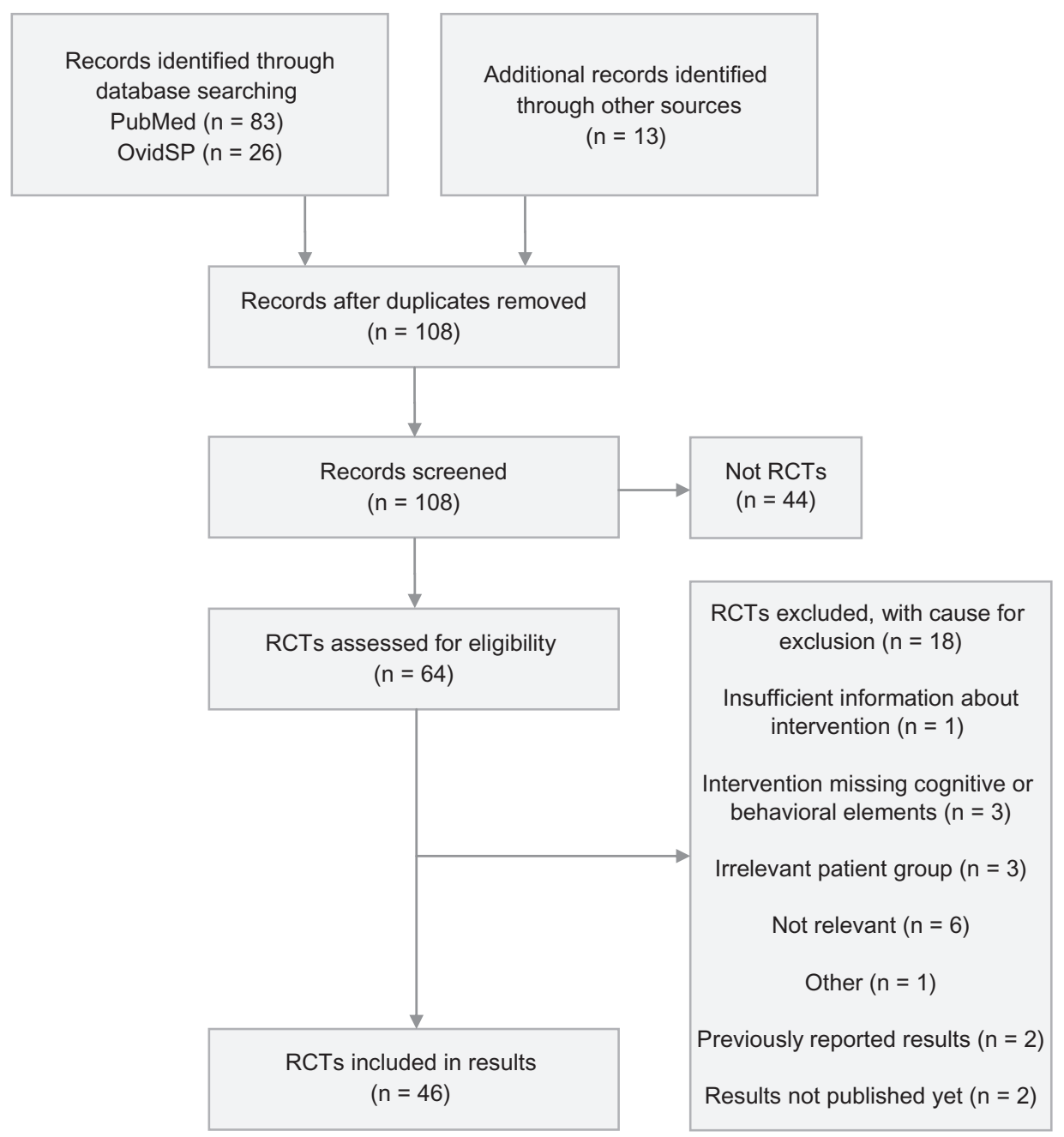

Figure I Flowchart of article selection.

Abbreviation: RCTs, randomized controlled trials.

Only RCTs and reviews of RCTs were included in the result section, while other and complementary studies were included in the discussion. Studies were required to deal with both chronic and nonspecific back pain. Some studies on acute or subacute back pain focusing on preventing chronicity were also included, based on considerations of relevance. Interventions were not required to have been pure CBT, but had to include both cognitive and behavioral components. Such interventions include problem-solving therapy, pain management, and acceptance and commitment therapy. Examples of excluded interventions were graded activity, exercise, and operant behavioral therapy without cognitive elements.

\section{Analysis, interpretation, and summary of studies}

All studies were examined for the abovementioned inclusion criteria. Eligible intervention studies and reviews were categorized by type of intervention and analyzed individually before each category was analyzed as a whole, constituting separate sections with respective summaries.

\section{Results}

46 RCTs investigating CBT compared to various interventions or investigating other aspects of $\mathrm{CBT}$, were included in the review. A number of reviews and other studies were also included for discussion purposes.

\section{Outcomes of CBT compared}

\section{Wait list controls/treatment as usual}

The majority of RCTs where the goal is to study the effects of CBT compare the active intervention (CBT) with treatment as usual or a wait list control. Compared to such control groups, CBT appears to be an advantageous and recommendable treatment for chronic back pain. 
Compared to usual care, a cognitive program with CBT, goal-setting, and goal-pursuit strategy led to increased physical capacity. ${ }^{26}$ Another study showed that when adding cognitive coping skills training to an operant behavioral treatment, reports of activity tolerance, pain control, and pain coping increased, while negative affect (catastrophizing, pain intensity, depression, and fear) and pain behavior decreased compared to wait-list controls. ${ }^{27,28}$

When considering the overall effects of these studies, CBT treatments show the following benefits over wait-list control: reduced pain, ${ }^{29-38}$ anxiety, ${ }^{30}$ avoidance, ${ }^{33}$ backrelated worry, ${ }^{39}$ catastrophizing, ${ }^{29,32,33,40,41}$ depression, ${ }^{30,35,37}$ disability, ${ }^{31-33,37,38,42}$ disabling attitudes and beliefs, ${ }^{31,32,35,39}$ and stress, ${ }^{30}$ and increased coping, ${ }^{30,37}$ health-related quality of life (for females only), ${ }^{43}$ pain control, ${ }^{33,37}$ pain self-efficacy, ${ }^{31,32}$ perceived ability to function, ${ }^{44}$ physical health-related quality of life, ${ }^{31}$ quality of life in general, ${ }^{41}$ and social support. ${ }^{30}$ It has also demonstrated effects on occupational and economic outcomes in terms of cost-effectiveness, ${ }^{31,45}$ health care visits, ${ }^{46}$ reduction in sick days/work days lost, ${ }^{46,47}$ and return to work. ${ }^{42}$

Despite these overall positive effects, some of the smaller studies did report a lack of effect on several relevant outcome measures or improvements in the control conditions as well. ${ }^{29,41,44}$ Also, a few studies reported no differences between the CBT and control groups, or marginal effects that were not maintained at follow-up. ${ }^{48-51}$

Nevertheless, the vast majority of evidence comparing CBT with wait-list controls or treatment as usual supports the beneficial effects of CBT for chronic back pain.

\section{Information/education}

Advice to stay active and resume usual activities and work as soon as possible are recommendations highly emphasized in the clinical guidelines for the management of LBP. ${ }^{4}$ These educational components are therefore likely to be included as part of treatment as usual, as described in the previous paragraph. There are, however, few studies that compare CBT to educational information where this has been made explicit and structured into an intervention.

In a group of acute and subacute back- and neck-pain patients who believed they were at risk for developing chronic problems, the effect of a CBT that aimed to prevent chronicity was compared to an information pamphlet that aimed to prevent fear avoidance and promote coping, and to an extensive information package based on a back school approach. ${ }^{52}$ The results showed a ninefold reduction in risk for long-term sick leave and significantly less health care use in the CBT group. A 5-year follow-up of both health and economic consequences showed sustained effects of the CBT on pain, activity, quality of life, general health, productivity, and economic costs, and a three times higher risk of longterm sick leave in the two information groups. ${ }^{53}$ Another study compared a group education program combined with behavioral graded activity with a cognitive intervention of problem-solving therapy and graded activity. The CBT intervention resulted in significantly fewer days of sick leave, more employees with 100\% return-to-work, and fewer disability pensioners 1 year after the intervention. ${ }^{54}$ The results from these trials thus seem to support the same results as the comparison with treatment as usual, with CBT interventions showing higher effects than educational approaches.

\section{Physical treatments/exercise}

Encouraging physical activity is a cornerstone of musculoskeletal rehabilitation, and supervised exercise therapy is recommended as a first-line treatment in the management of chronic LBP. ${ }^{4}$ While there is strong evidence that exercise therapy is more effective than normal care in general practice, ${ }^{4}$ the comparison to $\mathrm{CBT}$ or various CBT approaches is less clear.

CBT has been compared to a range of different physical treatments and exercise programs, including exercise treatment with aerobic, strength- and stretching exercises, operant graded activity, physiotherapy, preventive physiotherapy and behavioral-oriented physiotherapy.

A cognitive intervention based on the noninjury model showed similar or better outcomes than a symptom-based physical exercise, despite fewer treatment sessions. ${ }^{55}$ When CBT was compared with exercise therapy and a combination of the two, all three treatments were found to be effective in reducing functional limitations, pain intensity, and related outcomes compared with no treatment. However, no clinically relevant differences between the three treatments could be detected. ${ }^{38}$ A reduction in pain catastrophizing seemed to be the crucial mediator of outcome in all of the treatments. ${ }^{40}$ Results were fairly consistent at 1-year follow-up, showing that a combination of CBT and exercise may not be a better treatment option than exercise or CBT alone. ${ }^{56}$ Similar results were found in another study investigating sick leave, early retirement, and health-related quality of life, where the separate components of a behavioral medicine rehabilitation program were as good as the full combined program. ${ }^{43}$ When a 10-year follow-up assessment was conducted, the combined program still showed effects on sick leave, while the separate CBT and physiotherapy interventions showed no effect on this outcome. ${ }^{48}$ 
Combined treatments that involve CBT components have been found to be superior to exercise alone on functional impairment, active coping strategies, self-efficacy beliefs, use of medication, ${ }^{57}$ perceptions of severity and barriers, and selfreported frequency of exercise, ${ }^{58}$ although these studies are fairly small. Also, a combined treatment of behavioral graded activity and problem-solving therapy added to the effect of behavioral graded activity alone, regarding days of sick leave and work status. ${ }^{54}$ Another study showed that combined treatments were not more effective in reducing health care utilization and work absenteeism than CBT alone. ${ }^{46}$

Despite a few exceptions, the combination of exercise therapy and CBT seems to be no more beneficial than the separate elements alone. Some evidence does, however, point in the direction of combinations being more beneficial than exercise, while not being more beneficial than CBT. Essentially, the combined evidence indicates that $\mathrm{CBT}$, whether alone or in combination with exercise therapy, is more or equally beneficial as exercise therapy in treating chronic back pain.

\section{Operant behavioral treatment}

Operant treatments for LBP share similarities with the physical treatments and exercise discussed above, though it is more specific in its focus on behavioral elements such as increasing health behaviors and activity levels while decreasing pain behaviors and disability using principles of operant conditioning. ${ }^{59,60}$

The evidence is generally conflicting for the comparison of $\mathrm{CBT}$ and operant behavioral treatments. Kole-Snijders et a ${ }^{28}$ combined an operant behavioral treatment including spouse training, treatment contacts, and individual counseling, with a cognitive treatment aimed at increasing coping skills and self-efficacy expectations. Compared to the operant program with attention control, both programs were equally effective in reducing negative affect and pain behavior and increasing activity tolerance, pain coping, and pain control when compared to wait-list controls. A cognitive program thus had a limited added value, besides improving pain coping and pain control. A health economic assessment of the study showed that the added cognitive element led to no significant differences in costs and improvement in quality of life compared to the operant treatment alone. ${ }^{61}$ Another study showed better results of an operant therapy on pain behavior and physical and psychosocial functioning compared to a combined treatment with CBT, although the differences were not maintained at follow-up. ${ }^{49}$ The opposite has also been found, where a cognitive treatment showed better results when added to an operant treatment, and these results were maintained at follow-up..$^{62}$
The conflicting results make it difficult to draw any conclusions in terms of any added effects of cognitive therapy to operant therapy. One reason may be that the operant programs tend to be fairly comprehensive and interdisciplinary, containing elements that are also found in CBT such as individual adaption and goal-setting with follow-up and structured feedback. This could result in an additional cognitive program being excessive.

\section{Biofeedback}

Electromyographic biofeedback involves using feedback from individual bodily processes in combination with training aimed at manipulating them with the purpose of improving health and performance. A combined treatment of CBT and electromyographic biofeedback was found to be beneficial in reducing pain intensity and related symptomatology in chronic back-pain patients, but not more so than CBT alone. ${ }^{63}$ Similar results were found in a comparison of CBT versus electromyographic biofeedback in chronic LBP patients, which showed equal improvements in measures of pain intensity, perceived level of disability, adaptive beliefs about pain, and level of depression, with no significant differences between the conditions..$^{35} \mathrm{~A}$ study of prevention of chronicity in patients with acute sciatic pain showed risk-factor-based CBT, based strictly on individual psychosocial risk factors, to be superior to electromyographic biofeedback with respect to pain relief and application for early retirement, although both treatments were shown to be beneficial. ${ }^{64}$

The current knowledge about electromyographic biofeedback when compared to CBT in treating chronic nonspecific LBP is very scarce. Out of the few existing studies, two include very few participants, ${ }^{35,64}$ while one also had some methodological limitations to the randomization process. ${ }^{35}$ Nonetheless, the existing studies indicate that electromyographic biofeedback might be a beneficial treatment for chronic muscle pain, though not necessarily resulting in improved outcomes as compared to CBT, whether it is alone or in combination with CBT.

\section{Lumbar spinal fusion surgery}

Surgery may be the utmost opposite of cognitive behavioral treatment, and there is an ongoing discussion of the relative effectiveness of surgical versus nonsurgical interventions. During the last decade, a few RCTs have been conducted to compare spinal fusion with $\mathrm{CBT}$ in patients with chronic LBP, all having fairly concordant outcomes.

Brox et $\mathrm{al}^{65}$ compared lumbar fusion and postoperative physiotherapy to a cognitive intervention, based on the 
non-injury model. ${ }^{55}$ The cognitive intervention consisted of a lecture addressing pain avoidance and pain related fear. The patients were recommended to use and bend their back while engaging in normal activity along with daily reinforcement during exercises and group discussions. Both intervention groups showed equal improvement in the Oswestry Disability Index (ODI). Similar results were found in a study where patients that still had LBP 1 year postsurgery for disc herniation were included. ${ }^{66} \mathrm{~A}$ 4-year follow-up of the two studies combined showed consistent results in that the long-term recovery was the same after the surgical treatments compared with the cognitive intervention and exercises. ${ }^{67}$ The authors argue that spinal fusion, although undoubtedly effective for some conditions, fails to show any benefit over cognitive intervention and exercises. They also argue that the procedure may be overused, and point to the increasing rates of surgery combined with high rates of complications and reoperations. ${ }^{66}$ In the same material, there was an increase in muscle strength at 1-year follow-up in the combined cognitive intervention and exercise groups compared to the lumbar fusion groups, in which density decreased significantly compared with the combined cognitive intervention and exercise. ${ }^{68} \mathrm{~A} 7-11$-year follow-up showed no difference in muscle strength, crosssectional area, or muscle density above the lesion in the two groups. ${ }^{69}$ Similarly, Fairbank et al ${ }^{70}$ compared primary spinal fusion with an intensive rehabilitation program based on principles of CBT. They found none or marginal statistical group differences in walking capacity and ODI respectively, giving no clear evidence of surgery being more beneficial than intensive rehabilitation.

Existing studies comparing surgical and nonsurgical cognitive treatments for nonspecific LBP do not indicate beneficial short-term nor long-term effects of surgery for LBP. Additionally, the potential risk and costs of surgery need to be taken into account, and the existing evidence gives reason to doubt the advantage of surgical approaches over cognitive intervention and exercise. Although the relevant studies have been criticized for sample size, lack of power and general clinical importance, ${ }^{71}$ they show consistence in general findings throughout long-term follow-up, and provide interesting and important findings for further investigation.

\section{Relaxation training}

Several studies use combinations of CBT and relaxation training, but fewer investigations have contrasted the two

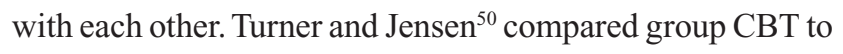
systematic progressive muscle relaxation and imagery, a combination of the two, and a control condition. Results showed no significant differences between any of the treatments, but depressive symptoms and disability improved in all conditions. Results were maintained at 6- and 12-month follow-up. Also, Nicholas et $\mathrm{al}^{72}$ found progressive muscle relaxation training to add little to a cognitive treatment program.

Both studies included very few participants. Although the amount of evidence is scarce at best, it indicates that relaxation training is not more beneficial than $\mathrm{CBT}$, and does not provide an additional effect to CBT, possibly due to similarity and overlap between the two.

\section{Discussion}

\section{Outcomes and effectiveness of CBT}

In general, the results point to CBT in the management of back pain as a beneficial treatment leading to improvements in a wide range of relevant variables. This is especially apparent in comparisons of CBT with wait-list controls/ treatment as usual, to some extent when compared with physical treatments/exercise, information/education, and lumbar spinal fusion surgery, and to a lesser extent when compared to biofeedback, operant behavioral treatment, and relaxation training.

Although the body of evidence predominantly points to positive effects of CBT, the results are still inconsistent and conflicting. There is reason to believe that certain individual characteristics lead to increased receptiveness to CBT treatments, as such treatments highly depend on self-management. ${ }^{73}$ Such intrapersonal factors involve beliefs about treatment credibility and expectancy, both strongly associated with the outcome of CBT. ${ }^{74}$ Addressing these factors may be important in preparing treatment, by measuring participants' beliefs about credibility and expectancies a priori, and by explaining the rationale, underlying principles, and evidence of CBT at a preliminary stage. ${ }^{75}$ Interpersonal factors in the patient-therapist relation may also play a role in amenability to CBT. Maiers et al $^{76}$ discovered that CBT was the modality most often declined by the patients in a multidisciplinary integrative care program, while also being the most commonly added modality if additional care was necessary. The same study also showed that previously wary participants were more willing to try CBT when having established a primary relationship to another clinician. ${ }^{76}$

\section{Variances in duration and implementation of CBT}

CBT can take many shapes and forms, and varying applications of the therapy are more often the rule rather than the exception. CBT may be provided as individual or 
group therapy, in sessions of different durations, and as a one-time occurrence or a long-term commitment. Such differences in the application of CBT may well influence the effect of the therapy. However, a comparison of group versus individual treatment using cognitive behavioral principles in a pain-management program showed improvement to be generally independent of whether patients were treated as part of a group or individually. Also, a comparison of 15-, 30-, or 60-hour programs indicated the same lack of difference. ${ }^{77}$ Although this may seem surprising, the findings may be due to the principles of CBT being consistent across situations and thereby providing the same cognitive message independently of these factors. Whether the patient catches this message may be unrelated to location or duration. Nevertheless, this is highly uncertain and these results alone are not sufficient to draw any firm conclusions. Future investigation of the significance of these factors is important, especially concerning the potential economic and clinical implications of such variations in the implementation of CBT.

Using web-based technology as a medium may be a cost-effective way of administering CBT as well as being time-saving and widely available across social groups and locations. It may reduce the potential stigma of seeing a therapist, as well as barriers related to physical disability. Building on a concept of guided self-help treatment, these interventions can include support, correspondence, and individual feedback by phone or email. Internet-based cognitive interventions have been developed for a wide variety of physiological, psychological, and behavioral health problems, ${ }^{78-83}$ and a systematic review shows results to be comparable to the effects found for face-to-face treatments. ${ }^{84}$ Some of the previously discussed studies of CBT for back pain were internetbased, ${ }^{29,30,32,41}$ showing improvements in measures of anxiety, catastrophizing, coping, depression, disability, disabling attitudes and beliefs, mood regulation, pain, self-efficacy for pain control, social support, and stress, with follow-up data showing long-term effects to be somewhat maintained.

Although very few studies have been conducted comparing internet-based and traditional CBT, internet-based CBT shows some promise as a simple yet effective treatment for back pain. It may be provided as a stand-alone intervention or as an addition to existing treatments, and is likely to become increasingly popular in the future.

\section{Pure CBT or addition and integration of CBT elements}

Pure CBT interventions that follow clearly structured protocols are relatively rare. Most of the studies in the current review involve multidisciplinary combinations or the mere addition of cognitive or behavioral elements to other treatments. This complicates the review process somewhat as we want to make sure we are talking about the same thing, comparing fairly similar interventions. Corresponding caution is also warranted when it comes to generalization of findings, where a mere referral to "CBT" in many cases is insufficient and needs further specification.

Several studies involve interventions in which principles from CBT are applied but where there are insufficient elements to refer to it as an actual CBT intervention. CBT principles have, for instance, been applied in a couple of studies involving psychoeducational treatment programs, ${ }^{37,55}$ as well as in various rehabilitation programs. ${ }^{70}$

The combination of CBT with other treatment components and interventions can further be divided in two broad categories: multidisciplinary and transdisciplinary interventions. In multidisciplinary interventions, CBT occurs as an added element to other treatments, whilst in the more recent transdisciplinary interventions, the CBT is integrated with other disciplinary approaches. Examples of the former includes, for instance, combinations of CBT and medical treatments, ${ }^{33,85} \mathrm{CBT}$ and biofeedback, ${ }^{63} \mathrm{CBT}$ and operant behavioral treatment, ${ }^{28} \mathrm{CBT}$ and relaxation, ${ }^{50,61}$ and $\mathrm{CBT}$ and various forms of physiotherapy ${ }^{38,46,57}$ As described earlier, the addition of CBT offers additional benefits in some cases, whilst no added benefits over comparison treatments in others. Common for all of them are still the distinction between the CBT and the other treatment components. Examples of transdisciplinary interventions where the CBT is not only added, but also consistently integrated into the intervention, are still scarce, but one recent study has shown particular promise in returning chronic LBP patients to work using an integrated, transdisciplinary approach. ${ }^{42}$ The integrated intervention consisted of a clinical intervention, graded activity as a cognitive behavioral intervention, a workplace intervention to reduce barriers in the workplace based on participatory ergonomics, and occupational health care. All were integrated into mainstream health care, involving all necessary stakeholders, to reduce system barriers. ${ }^{42}$ The economic evaluation of the intervention further showed large gains for both patients and society as well as for employers. ${ }^{45}$ In patients for whom chronic LBP results in long-term work disability, these new integrated approaches may be the start of a paradigm shift in the disability management, where not only biological, psychological, and social factors are acknowledged and addressed, but also the interplay involving the relevant stakeholders. ${ }^{86,87}$ 


\section{Conclusion}

The results of this review primarily point to CBT as a beneficial treatment for chronic nonspecific back pain, leading to improvements in a wide range of relevant cognitive, behavioral, and physical variables. This is especially evident when CBT is compared to treatment as usual or wait-list controls, but mixed and inconclusive when compared with various other treatments. Multidisciplinary and transdisciplinary interventions that integrate CBT with other approaches may represent the future direction of management of chronic back pain, with treatments modified for specific circumstances and stakeholders. Individual expectancies and beliefs about treatment credibility may be important factors for receptiveness to treatment, and addressing these factors a priori may be imperative to improve the outcomes of CBT.

The current evidence emphasizes the large variety of approaches and methodology in the implementation of CBT, and the frequent use of cognitive behavioral elements as an addition to other forms of management. In order for interventions labeled CBT to be better compared and generalized across different interventions and populations, we recommend that future research should aim for more specific descriptions of the procedures and elements of the intervention being investigated.

\section{Disclosure}

The authors report no conflicts of interest or external sources of funding in this work.

\section{References}

1. Beck JS. Cognitive Therapy: Basics and Beyond. 1st ed. New York: Guilford Press; 1995.

2. Deary V, Chalder T, Sharpe M. The cognitive behavioural model of medically unexplained symptoms: a theoretical and empirical review. Clin Psychol Rev. 2007;27(7):781-797.

3. Burton AK, Balagué F, Cardon G, et al; COST B13 Working Group on Guidelines for Prevention in Low Back Pain. Chapter 2. European guidelines for prevention in low back pain: November 2004. Eur Spine J. 2006;15 Suppl 2:S136-S168.

4. Airaksinen O, Brox JI, Cedraschi C, et al; COST B13 Working Group on Guidelines for Prevention in Low Back Pain. European guidelines for the management of chronic nonspecific low back pain. Eur Spine J. 2006;15 Suppl 2:S192-S300.

5. Prithvi Raj P. Taxonomy and classification of pain. In: Kreitler S, Beltrutti D, editors. The Handbook of Chronic Pain. New York: Nova Science Publishers; 2007:41-56.

6. Freburger JK, Holmes GM, Agans RP, et al. The rising prevalence of chronic low back pain. Arch Intern Med. 2009;169(3):251-258.

7. Rubin DI. Epidemiology and risk factors for spine pain. Neurol Clin. 2007;25(2):353-371.

8. Balagué F, Mannion AF, Pellisé F, Cedraschi C. Non-specific low back pain. Lancet. 2012;379(9814):482-491.

9. Cho NH, Jung YO, Lim SH, Chung CK, Kim HA. The prevalence and risk factors of low back pain in rural community residents of Korea. Spine (Phila Pa 1976). Epub May 25, 2012.
10. Turk Z, Vauhnik R, Micetić-Turk D. Prevalence of nonspecific low back pain in schoolchildren in north-eastern Slovenia. Coll Antropol. 2011;35(4):1031-1035.

11. Osborne A, Blake C, Fullen BM, et al. Prevalence of musculoskeletal disorders among farmers: a systematic review. Am J Ind Med. 2012;55(2): $143-158$

12. Andersen LL, Mortensen OS, Hansen JV, Burr H. A prospective cohort study on severe pain as a risk factor for long-term sickness absence in blueand white-collar workers. Occup Environ Med. 2011;68(8):590-592.

13. Beltrutti D, Lamberto A, Nicoscia M, Marino F. Low back pain. In: Kreitler S, Beltrutti D, editors. The Handbook of Chronic Pain. New York: Nova Science Publishers; 2007:465-488.

14. Reme SE, Eriksen HR, Ursin H. Cognitive activation theory of stress how are individual experiences mediated into biological systems? SJWEH Supplement. 2008;6:177-183.

15. Vlaeyen JW, Kole-Snijders AM, Boeren RG, vanEek H. Fear of movement/ (re)injury in chronic low back pain and its relation to behavioral performance. Pain. 1995;62(3):363-372.

16. Burton AK, Tillotson KM, Main CJ, Hollis S. Psychosocial predictors of outcome in acute and subchronic low back trouble. Spine. 1995;20(6): $722-728$.

17. Linton SJ. A review of psychological risk factors in back and neck pain. Spine. 2000;25(9):1148-1156.

18. Hoogendoorn WE, van Poppel MN, Bongers PM, Koes BW, Bouter LM. Systematic review of psychosocial factors at work and private life as risk factors for back pain. Spine. 2000;25(16):2114-2125.

19. Pincus T, Burton AK, Vogel S, Field AP. A systematic review of psychological factors as predictors of chronicity/disability in prospective cohorts of low back pain. Spine. 2002;27(5):E109-E120.

20. van Tulder MW, Ostelo R, Vlaeyen JW, Linton SJ, Morley SJ, Assendelft WJ. Behavioral treatment for chronic low back pain: a systematic review within the framework of the Cochrane Back Review Group. Spine. 2000;26(3):270-281.

21. Turner JA. Educational and behavioral interventions for back pain in primary care. Spine. 1996;21(24):2851-2857.

22. Brox JI, Storheim K, Grotle M, Tveito TH, Indahl A, Eriksen HR. Systematic review of back schools, brief education, and fear-avoidance training for chronic low back pain. Spine J. 2008;8(6):948-958.

23. Roelofs J, Boissevain MD, Peters ML, de Jong JR, Vlaeyen JW. Psychological treatments for chronic low back pain: Past, present and beyond. Pain Reviews. 2002;9(1):29-40.

24. Henschke N, Ostelo RW, van Tulder MW, et al. Behavioural treatment for chronic low-back pain. Cochrane Database Syst Rev. 2010;7(7):CD002014.

25. van Geen JW, Edelaar MJ, Janssen M, van Eijk JT. The long-term effect of multidisciplinary back training: a systematic review. Spine. 2007;32(2):249-255.

26. Christiansen S, Oettingen G, Dahme B, Klinger R. A short goal-pursuit intervention to improve physical capacity: a randomized clinical trial in chronic back pain patients. Pain. 2010;149(3):444-452.

27. Spinhoven P, Ter Kuile M, Kole-Snijders AM, Hutten Mansfeld M, Den Ouden DJ, Vlaeyen JW. Catastrophizing and internal pain control as mediators of outcome in the multidisciplinary treatment of chronic low back pain. Eur J Pain. 2004;8(3):211-219.

28. Kole-Snijders AM, Vlaeyen JW, Goossens ME, et al. Chronic lowback pain: what does cognitive coping skills training add to operant behavioral treatment? Results of a randomized clinical trial. $J$ Consult Clin Psychol. 1999;67(6):931-944.

29. Buhrman M, Faltenhag S, Strom L, Andersson G. Controlled trial of Internet-based treatment with telephone support for chronic back pain. Pain. 2004;111(3):368-377.

30. Chiauzzi E, Pujol LA, Wood M, et al. painACTION-back pain: a selfmanagement website for people with chronic back pain. Pain Med. 2010;11(7):1044-1058.

31. Lamb SE, Hansen Z, Lall R, et al. Group cognitive behavioural treatment for low-back pain in primary care: a randomised controlled trial and cost-effectiveness analysis. Lancet. 2010;375(9718):916-923. 
32. Carpenter KM, Stoner SA, Mundt JM, Stoelb B. An online selfhelp CBT intervention for chronic lower back pain. Clin J Pain. 2012;28(1):14-22.

33. Basler HD, Jäkle C, Kröner-Herwig B. Incorporation of cognitivebehavioral treatment into the medical care of chronic low back patients: a controlled randomized study in German pain treatment centers. Patient Educ Couns. 1997;31(2):113-124.

34. Basler HD. Group treatment for pain and discomfort. Patient Educ Couns. 1993;20(2-3):167-175.

35. Newton-John TR, Spence SH, Schotte D. Cognitive-behavioural therapy versus EMG biofeedback in the treatment of chronic low back pain. Behav Res Ther. 1995;33(6):691-697.

36. Menzel NN, Robinson ME. Back pain in direct patient care providers: early intervention with cognitive behavioral therapy. Pain Manag Nurs 2006;7(2):53-63.

37. Strong J. Incorporating cognitive-behavioral therapy with occupational therapy: a comparative study with patients with low back pain. J Occup Rehabil. 1998;8(1):61-71.

38. Smeets RJ, Vlaeyen JW, Hidding A, et al. Active rehabilitation for chronic low back pain: Cognitive-behavioral, physical, or both? First direct post-treatment results from a randomized controlled trial. BMC Musculoskelet Disord. 2006;7(1):5.

39. Moore JE, Von Korff M, Cherkin D, Saunders K, Lorig K. A randomized trial of a cognitive-behavioral program for enhancing back pain self care in a primary care setting. Pain. 2000;88(2):145-153.

40. Smeets RJ, Vlaeyen JW, Kester AD, Knottnerus JA. Reduction of pain catastrophizing mediates the outcome of both physical and cognitive-behavioral treatment in chronic low back pain. J Pain. 2006;7(4):261-271.

41. Buhrman M, Nilsson-Ihrfeldt E, Jannert M, Strom L, Andersson G. Guided internet-based cognitive behavioural treatment for chronic back pain reduces pain catastrophizing: a randomized controlled trial. J Rehabil Med. 2011;43(6):500-505.

42. Lambeek LC, van Mechelen W, Knol DL, Loisel P, Anema JR. Randomised controlled trial of integrated care to reduce disability from chronic low back pain in working and private life. BMJ. 2010;340:c1035.

43. Jensen IB, Bergström G, Ljungquist T, Bodin L, Nygren ÅL. A randomized controlled component analysis of a behavioral medicine rehabilitation program for chronic spinal pain: are the effects dependent on gender? Pain. 2001;91(1-2):65-78.

44. Andersson G, Johansson C, Nordlander A, Asmundson GJ. Chronic pain in older adults: a controlled pilot trial of a brief cognitive-behavioural group treatment. Behav Cogn Psychother. 2012;40(2):239-244.

45. Lambeek LC, Bosmans JE, Van Royen BJ, Van Tulder MW, Van Mechelen W, Anema JR. Effect of integrated care for sick listed patients with chronic low back pain: economic evaluation alongside a randomised controlled trial. BMJ. 2010;341:c6414.

46. Linton SJ, Boersma K, Jansson M, Svard L, Botvalde M. The effects of cognitive-behavioral and physical therapy preventive interventions on pain-related sick leave: a randomized controlled trial. Clin J Pain. 2005;21(2):109-119.

47. Schweikert B, Jacobi E, Seitz R, et al. Effectiveness and cost-effectiveness of adding a cognitive behavioral treatment to the rehabilitation of chronic low back pain. J Rheumatol. 2006;33(12):2519-2526.

48. Bergström C, Jensen I, Hagberg J, Busch H, Bergström G. Effectiveness of different interventions using a psychosocial subgroup assignment in chronic neck and back pain patients: a 10-year follow-up. Disabil Rehabil. 2012;34(2):110-118.

49. Turner JA, Clancy S. Comparison of operant behavioral and cognitivebehavioral group treatment for chronic low back pain. J Consult Clin Psychol. 1988;56(2):261-266.

50. Turner JA, Jensen MP. Efficacy of cognitive therapy for chronic low back pain. Pain. 1993;52(2):169-177.

51. Lindell O, Johansson SE, Strender LE. Subacute and chronic, nonspecific back and neck pain: cognitive-behavioural rehabilitation versus primary care. A randomized controlled trial. BMC Musculoskelet Disord. 2008;9:172.
52. Linton SJ, Andersson T. Can chronic disability be prevented? A randomized trial of a cognitive-behavior intervention and two forms of information for patients with spinal pain. Spine. 2000;25(21):2825-2831.

53. Linton SJ, Nordin E. A 5-year follow-up evaluation of the health and economic consequences of an early cognitive behavioral intervention for back pain: a randomized, controlled trial. Spine. 2006;31(8): $853-858$.

54. van den Hout JH, Vlaeyen JW, Heuts PH, Zijlema JH, Wijnen JA. Secondary prevention of work-related disability in nonspecific low back pain: does problem-solving therapy help? A randomized clinical trial. Clin J Pain. 2003;19(2):87-96.

55. Sorensen PH, Bendix T, Manniche C, Korsholm L, Lemvigh D, Indahl A. An educational approach based on a non-injury model compared with individual symptom-based physical training in chronic LBP. A pragmatic, randomised trial with a one-year follow-up. $B M C$ Musculoskelet Disord. 2010;11:212.

56. Smeets RJ, Vlaeyen JW, Hidding A, Kester AD, van der Heijden GJ, Knottnerus JA. Chronic low back pain: physical training, graded activity with problem solving training, or both? The one-year posttreatment results of a randomized controlled trial. Pain. 2008;134(3): 263-276.

57. Nicholas MK, Wilson PH, Goyen J. Comparison of cognitive-behavioral group treatment and an alternative non-psychological treatment for chronic low back pain. Pain. 1992;48(3):339-347.

58. Göhner W, Schlicht W. Preventing chronic back pain: evaluation of a theory-based cognitive-behavioural training programme for patients with subacute back pain. Patient Educ Couns. 2006;64(1-3):87-95.

59. Skinner BF. Science and Human Behavior. New York: Macmillan; 1953.

60. Fordyce WE. Behavioral Methods for Chronic Pain And Illness. St Louis: Mosby; 1976.

61. Goossens ME, Rutten-Van Molken MP, Kole-Snijders AM, Vlaeyen JW, Van Breukelen G, Leidl R. Health economic assessment of behavioural rehabilitation in chronic low back pain: a randomised clinical trial Health Econ. 1998;7(1):39-51.

62. Vlaeyen JW, Haazen IW, Schuerman JA, Kole-Snijders AM, van Eek H. Behavioural rehabilitation of chronic low back pain: comparison of an operant treatment, an operant-cognitive treatment and an operant-respondent treatment. Br J Clin Psychol. 1995;34(Pt 1): 95-118.

63. Glombiewski JA, Hartwich-Tersek J, Rief W. Two psychological interventions are effective in severely disabled, chronic back pain patients: a randomised controlled trial. Int J Behav Med. 2010;17(2):97-107.

64. Hasenbring M, Ulrich HW, Hartmann M, Soyka D. The efficacy of a risk factor-based cognitive behavioral intervention and electromyographic biofeedback in patients with acute sciatic pain. An attempt to prevent chronicity. Spine. 1999;24(23):2525-2535.

65. Brox JI, Sorensen R, Friis A, et al. Randomized clinical trial of lumbar instrumented fusion and cognitive intervention and exercises in patients with chronic low back pain and disc degeneration. Spine. 2003;28(17):1913-1921.

66. Brox JI, Reikeras O, Nygaard O, et al. Lumbar instrumented fusion compared with cognitive intervention and exercises in patients with chronic back pain after previous surgery for disc herniation: a prospective randomized controlled study. Pain. 2006;122(1-2):145-155.

67. Brox JI, Nygaard OP, Holm I, Keller A, Ingebrigtsen T, Reikeras O. Four-year follow-up of surgical versus non-surgical therapy for chronic low back pain. Ann Rheum Dis. 2010;69(9):1643-1648.

68. Keller A, Brox JI, Gunderson R, Holm I, Friis A, Reikeras O. Trunk muscle strength, cross-sectional area, and density in patients with chronic low back pain randomized to lumbar fusion or cognitive intervention and exercises. Spine. 2004;29(1):3-8.

69. Froholdt A, Holm I, Keller A, Gunderson RB, Reikeraas O, Brox JI. No difference in long-term trunk muscle strength, cross-sectional area, and density in patients with chronic low back pain 7 to 11 years after lumbar fusion versus cognitive intervention and exercises. The Spine Journal. 2011;11(8):718-725. 
70. Fairbank J, Frost H, Wilson-MacDonald J, Yu LM, Barker K, Collins R. Randomised controlled trial to compare surgical stabilisation of the lumbar spine with an intensive rehabilitation programme for patients with chronic low back pain: the MRC spine stabilisation trial. BMJ. 2005;330(7502):1233

71. Hägg O, Fritzell P. Re: Brox JI, Sorensen R, Friis A, et al. Randomized clinical trial of lumbar instrumented fusion and cognitive intervention and exercises in patients with chronic low back pain and disc degeneration. Spine. 2003;28:1913-1921. Spine (Phila Pa 1976). 2004;29(10):1160-1161.

72. Nicholas MK, Wilson PH, Goyen J. Operant-behavioural and cognitivebehavioural treatment for chronic low back pain. Behav Res Ther. 1991;29(3):225-238.

73. Ursin H, Eriksen HR. The cognitive activation theory of stress. Psychoneuroendocrinology. 2004;29:567-592.

74. Vlaeyen JW, Morley S. Cognitive-behavioral treatments for chronic pain: what works for whom? Clin J Pain. 2005;21(1):1-8.

75. Smeets RJ, Beelen S, Goossens ME, Schouten EG, Knottnerus JA, Vlaeyen JW. Treatment expectancy and credibility are associated with the outcome of both physical and cognitive-behavioral treatment in chronic low back pain. Clin J Pain. 2008;24(4):305-315.

76. Maiers MJ, Westrom KK, Legendre CG, Bronfort G. Integrative care for the management of low back pain: use of a clinical care pathway. BMC Health Serv Res. 2010;10:298.

77. Rose MJ, Reilly JP, Pennie B, Bowen-Jones K, Stanley IM, Slade PD. Chronic low back pain rehabilitation programs: a study of the optimum duration of treatment and a comparison of group and individual therapy. Spine. 1997;22(19):2246-2251.

78. Moritz S, Schilling L, Hauschildt M, Schroder J, Treszl A. A randomized controlled trial of internet-based therapy in depression. Behav Res Ther. 2012;50(7-8):513-521.
79. Lintvedt OK, Griffiths KM, Sørensen K, et al. Evaluating the effectiveness and efficacy of unguided internet-based self-help intervention for the prevention of depression: a randomized controlled trial. Clin Psychol Psychother. 2011;2(10):770.

80. Knaevelsrud C, Maercker A. Long-term effects of an internet-based treatment for posttraumatic stress. Cogn Behav Ther. 2010;39(1):72-77.

81. McDonnell DD, Kazinets G, Lee HJ, Moskowitz JM. An internet-based smoking cessation program for Korean Americans: results from a randomized controlled trial. Nicotine Tob Res. 2011;13(5):336-343.

82. Mansdorf IJ, Sharma R, Perez M, Lepore AM. Falls reduction in long-term care facilities: a preliminary report of a new internet-based behavioral technique. J Am Med Dir Assoc. 2009;10(9):630-633.

83. Carlbring P, Smit F. Randomized trial of internet-delivered self-help with telephone support for pathological gamblers. J Consult Clin Psychol. 2008;76(6):1090-1094.

84. Cuijpers P, van Straten A, Andersson G. Internet-administered cognitive behavior therapy for health problems: a systematic review. J Behav Med. 2008;31(2):169-177.

85. Kroenke K, Bair MJ, Damush TM, et al. Optimized antidepressant therapy and pain self-management in primary care patients with depression and musculoskeletal pain: a randomized controlled trial. JAMA. 2009;301(20):2099-2110.

86. Loisel P. Developing a new paradigm: Work disability prevention. ICOH. 2009;(Special issue): $1-5$.

87. Pransky GS, Loisel P, Anema JR. Work disability prevention research: current and future prospects. J Occup Rehabil. 2011;21(3):287-292.
Journal of Pain Research

\section{Publish your work in this journal}

The Journal of Pain Research is an international, peer-reviewed, open access, online journal that welcomes laboratory and clinical findings in the fields of pain research and the prevention and management of pain. Original research, reviews, symposium reports, hypothesis formation and commentaries are all considered for publication.

\section{Dovepress}

The manuscript management system is completely online and includes a very quick and fair peer-review system, which is all easy to use. Visit http://www.dovepress.com/testimonials.php to read real quotes from published authors. 